\title{
INFÂNCIA, EXCLUSÃO SOCIAL E EDUCAÇÃO COMO UTOPIA REALIZÁVEL"
}

\author{
Manuel Jacinto Sarmento"
}

\begin{abstract}
RESUMO: A infância, como construção social, tem sofrido, no decurso da $2^{\text {o }}$ modernidade, processos de reinstitucionalização que, em larga medida, põem em causa as representações e imagens das crianças, dominantes nos últimos 200 anos. A análise da (re)construção das identidades sociais e das subjectividades infantis constitui, desse modo, uma tarefa teórica da mais exigente actualidade. O que, entretanto, aqui se assinala é que este processo de reinstitucionalização da infância, apesar da construção de consensos globais sobre os direitos das crianças, tem vindo a aumentar os factores e as condições de exclusão das gerações mais jovens face aos direitos sociais e da cidadania. Neste artigo inventariam-se alguns dos principais indicadores de exclusão, considerando diversos espaços estruturais, e assinalam-se alguns dos pontos de ruptura por onde pode passar a construção de uma educação escolar centrada na afirmação activa dos direitos das crianças.
\end{abstract}

Palavras-chave: Infância. Exclusão social. Educação. Cidadania.

\section{CHILDHOOD, SOCIAL EXCLUSION AND EDUCATION AS A MANAGEABLE UTOPIA}

ABSTRACT: Along the second modernity, childhood, as a social construction, has undergone reinstatement processes that question the representations and images of children that have prevailed over last two hundred years. An analysis of the (re) construction of the social identities and childhood subjectivity thus constitute a theoretical task of the most contemporary exigence. Nevertheless, even though a global consensus about children's rights has been constructed, the increase of factors and conditions that exclude the youngest generations from social rights and citizenship, induced by this reinstatement process of childhood, is here emphasized. This paper lists some of the main indicators of exclusion, considering different structural spaces, and pinpoints some turning points through which the construction of a school education centered on the active affirmation of the children's rights could be attained.

Key words: Childhood. Social exclusion. Education. Citizenship

* $\quad$ Este texto fez parte da Mesa Temática: "Educação e políticas de exclusão: A negação dos direitos da Infância”, apresentada no Fórum Mundial de Educação (outubro de 2001), Porto AlegreRS (Brasil).

** Instituto de Estudos da Criança da Universidade do Minho (Braga, Portugal). E-mail: sarmento@iec.uminho.pt 

pintora portuguesa Paula Rego apresentou, em 1999, uma colecção temática dedicada à Cruzada das Crianças. Essa Cruzada foi um acontecimento histórico, ocorrido em 1212, no qual multidões de crianças, atraídas e arrebatadas pela Igreja Católica, se mobilizaram para atravessar a Europa, dirigindo-se para o Mediterrâneo, com a intenção de se deslocarem para Jerusalém e combater os muçulmanos. No entanto, não chegaram ao seu destino: ao longo do percurso e na travessia do Mediterrâneo, foram dizimadas por bandos de salteadores e de corsários, tendo alguns milhares morrido em consequência da fome e da violência.

A pintura de Paula Rego apresenta as crianças vestidas com roupas contemporâneas, ainda que seja uma forte impressão de dôr e abandono aquela que é transmitida pelos bandos erráticos de crianças em torno da sua cruz. Há, certamente, uma significativa mensagem de denúncia nesta gravura por parte de quem, ao longo da sua obra, tem dedicado às crianças e às mulheres uma parte fundamental da sua pintura expressionista. É lícito, portanto, considerar a cruzada das crianças como a metáfora plástica da situação social da infância contemporânea.

Se considerarmos os indicadores mais recentes sobre a situação da infância no Mundo (Unicef, 2000) - com os seus expressivos indicadores sobre a mortalidade infantil em consequência da guerra, da fome ou da doença - a metáfora ganha uma propriedade absoluta: na modernidade tardia ganha plena actualidade a barbárie medieval. No entanto, isso é paradoxal: 10 anos após a proclamação da Convenção dos Direitos da Criança, nunca como agora foram tão amplas as políticas de protecção das crianças.

O que a metáfora da Cruzada das Crianças eloquentemente ilustra é que a situação do sofrimento de milhões de crianças se inscreve hoje no coração da segunda modernidade e isso deve-se menos à insuficiência das proclamações proteccionistas ou da adopção de políticas específicas dirigidas para a infância e mais a factores estruturais. Tal como na Idade Média, foram os interesses e os valores do feudalismo reinante e da ideologia hegemónica que conduziram as crianças à errância pelos caminhos da destruição, é a profunda desigualdade da sociedade contemporânea que produz a situação da infância. E, portanto, a condição estrutural da infância, no quadro do sistema social, o que importa analisar e mudar, considerando a reformulação das identidades na modernidade tardia, e a adopção de políticas sociais de efectiva transformação e mudança das realidades sociais que promovem a exclusão.

No momento em que nos surgem nos jornais diariamente imagens de crianças vítimas de novas cruzadas conduzidas pelos poderes belicistas 
hegemónicos, rever a gravura de Paula Rego é também procurar encontrar as respostas para que, nos planos social e educacional, se possam promover as correntes contra-hegemónicas promotoras de uma infância verdadeiramente investida de direitos.

Nesta comunicação começaremos por apresentar os indicadores de exclusão social da infância, para depois nos colocarmos perante a questão das respostas educacionais para a inserção social.

\section{Infância e exclusão social}

Uma rápida leitura sobre os títulos dos jornais induzir-nos-ia facilmente à conclusão de que há uma crise social da infância. Esta imagem recorrente da geração jovem a percorrer itinerários de ruptura, de exclusão ou de desviância social é construída a partir de títulos e imagens que remetem para questões como as drogas, os maus-tratos infantis, a violência, a Sida etc. Por vezes, surgem referências a políticas sociais públicas que precisamente se procuram confrontar com as "crianças e jovens em perigo/ risco". Outras vezes são as crianças que aparecem como destinatários da violência social (por exemplo, como vítimas da guerra, ou alvo de agressões racistas ou pedófilas, ou ainda do desemprego e da pobreza). Em contrapartida, raras são as referências a iniciativas que atribuam às crianças o papel de agentes activos na construção da agenda social e política. O mundo da infância aparece invadido pela morte, pela injustiça (ou o mesmo é dizer, pela ausência ou ineficácia da justiça), pela doença, pelo desconforto, pelo abandono e pela violência.

Talvez se possa afirmar que os "fait-divers" dos adultos são igualmente caracterizados por tudo o que foge à "normalidade" dos dias - e isso é muito mais intensamente expresso como "patbos" do que como euforia ou espanto. Com efeito, são sobretudo "fait-divers" o que os jornais contam das crianças. Não entanto, não há nos mundos relatados das crianças o contraponto da política ou do desporto, ou até da cultura, que, apesar de tudo, fazem da imagem veiculada pelos jornais um mundo adulto mais humanizado. Não é, com efeito, esse o caso do mundo da infância relatado pelos jornais: são a violência e a crise que predominam na imagem relatada dos quotidianos das crianças.

Não é certamente indiferente que as referências dos media às gerações mais jovens se constituam em torno desta polaridade: exclusãovitimização. Os títulos que fazem os jornais são a expressão de um sensocomum de onde emanam e que, simultaneamente, alimentam, pela produção de formas (e dos correspondentes conteúdos) que hegemonizam 
os modos simbólicos de apreensão da realidade. Deste modo se vai construindo a realidade, continuamente formatada pelos sistemas periciais e de difusão de massa.

No caso vertente, a infância emerge como uma geração onde se exprime a crise social. Concorrem para esta imagem vários factores: ela é a expressão de uma posição estrutural que coloca, efectivamente, as gerações mais jovens nos pontos cardinais dos indicadores de exclusão (por exemplo, o desemprego e a pobreza); ela é, igualmente, a expressão de uma ideologia difusa, conservadora e preconceituosa, difundida entre os adultos, que oscila na ambivalência que existe entre a percepção da "crise de valores" (de que o comportamento infanto-juvenil seria a consumada expressão) e uma exaltação da "infância" como o espaço imaginário da beleza, da paz e da inocência; mas é, finalmente, o produto de uma opacidade e, por consequência, de um medo: há entre as crianças (e também os jovens), os seus estilos de vida e modos de apreensão do mundo, e as gerações que detêm o poder (político, económico e simbólico) a suficiente incomunicabilidade para que, afinal, se saiba tão pouco das gerações mais jovens e para que o recurso ao estereotipo de uma geração em perigo tão clara e constantemente se tenha vindo a fazer.

\section{Indicadores estruturais}

Conhecer as crianças impõe, por suposto, conhecer a infância. Isto vale por dizer que os itinerários individuais, privados e singulares de cada criança só fazem completo sentido se perspectivados à luz das condições estruturais que constrangem e condicionam cada existência humana. Essas condições, relativamente a cada categoria geracional, constituem o pano de fundo sobre o qual intervém cada um dos actores, ou, dito de modo mais rigoroso, exprimem o conjunto de constrangimentos estruturais que cada membro da sociedade continuamente sofre, interpreta, reproduz e refaz na sua interacção com os outros.

A inclusão da "geração" como variável dependente - e também como independente, dada a natureza do processo de estruturação que a acção humana continuamente opera na sociedade, sendo, por esse motivo, os actores sociais, simultaneamente, produtores e reprodutores da estrutura social (Giddens, 1984) - na análise dos factores estruturais permite compreender o paradoxo atrás referido da infância ser simultaneamente a depositária da imagem da paz e a face mais visível do horror da violência e da barbárie: é que a exclusão social opera também nas variáveis geracionais (tal como nas diferenças de classe, de etnia ou de género), afectando de 
modo muito expressivo as crianças. Deste modo, mais do que de crise social da infância importa referir os efeitos geracionais da exclusão social.

Abordaremos, brevemente, os factores de exclusão por referência a quatro espaços estruturais (cf. Santos, 2000): ${ }^{1}$ o espaço da produção (onde focaremos a relação com o trabalho e com a distribuição da riqueza), o espaço doméstico, o espaço da cidadania (onde salientaremos a escola e a esfera política) e o espaço comunitário (evidenciando as relações de pares e as "culturas infanto-juvenis").

O espaço estrutural da produção é dominado por quatro pontos fundamentais no que respeita à exclusão social das crianças:

- Primeiro, a incidência da pobreza entre as gerações;

- Segundo, o trabalho infantil;

- Terceiro, os efeitos do desemprego nas gerações mais jovens;

- Quarto, a criação de novas desigualdades inerentes ao acesso desigual aos bens do mercado de produtos para a infância.

Relativamente ao primeiro ponto, importa sublinhar que é nos dois pólos geracionais opostos (infância/juventude e terceira idade) que os índices de pobreza são mais acentuados. Isto quer dizer que, tomando por referência o conjunto do grupo etário, há, percentualmente, mais crianças/ jovens pobres do que adultos pobres. Isso mesmo pode ser visto no Quadro 1 , relativo a um conjunto de países do hemisfério Norte.

\section{Quadro 1}

Comparação da taxa de pobreza por grupos etários

\begin{tabular}{|c|c|c|c|c|}
\hline País & Ano & Crianças & 3a Idade & Total \\
\hline Ale manha & 1994 & 11,6 & 5,1 & 8,5 \\
\hline Austrália & 1994 & 17,1 & 13,9 & 14,6 \\
\hline Austria & 1987 & 5,6 & 5,5 & 4,8 \\
\hline Bélgica & 1992 & 6,1 & 7,0 & 5,7 \\
\hline Canadá & 1994 & 16,0 & 3,1 & 11,4 \\
\hline Dinam arca & 1992 & 5,9 & 4,6 & 4,9 \\
\hline EUA & 1994 & 26,3 & 14,9 & 20,7 \\
\hline Eslováquia & 1992 & 2,2 & 0,5 & 1,7 \\
\hline Espanha & 1990 & 13,1 & 6,8 & 10,3 \\
\hline Finlândia & 1991 & 3,4 & 3,8 & 3,2 \\
\hline França & 1989 & 9,8 & 9,5 & 9,4 \\
\hline Holanda & 1991 & 8,4 & 3,3 & 6,5 \\
\hline Hungria & 1994 & 11,5 & 6,6 & 9,9 \\
\hline Inglaterra & 1995 & 21,3 & 5,8 & 15,1 \\
\hline
\end{tabular}




\begin{tabular}{|c|c|c|c|c|}
\hline Irlanda & 1987 & 14,8 & - & 12,2 \\
\hline Israel & 1992 & 14,7 & 11,2 & 12,0 \\
\hline Itália & 1995 & 21,2 & 8,4 & 15,6 \\
\hline Luxemburgo & 1994 & 6,3 & 1,8 & 4,4 \\
\hline Noruega & 1995 & 4,5 & 1,2 & 3,1 \\
\hline Polónia & 1992 & 14,2 & 9,5 & 11,6 \\
\hline Rep. Checa & 1992 & 1,8 & 0,5 & 1,3 \\
\hline Rússia & 1995 & 26,6 & 16,3 & 22,8 \\
\hline Suécia & 1992 & 3,7 & 1,8 & 2,9 \\
\hline Suíca & 1982 & 6,3 & - & 5,5 \\
\hline Taiwan & 1995 & 6,3 & 11,3 & 6,6 \\
\hline
\end{tabular}

Fonte: Bradbury \& Jantti (1999)

\section{Quadro2}

\section{Evolução da Pobreza Infantil em Alguns Países Ocidentais}

\begin{tabular}{|c|c|c|c|c|c|c|c|}
\hline País & $\begin{array}{c}\text { Ano de } \\
\text { Inquénito }\end{array}$ & $<1970$ & $\underset{70}{10 \text { lustro de }}$ & $\underset{70}{20}$ lustro de & $\underset{80}{10}$ lustro de & $\underset{80}{2^{0} \text { lustro de }}$ & $>1990$ \\
\hline Alemanha & $\begin{array}{c}73,78,83 / 84 \\
89,94\end{array}$ & & 4.0 & 3.2 & $4.8 / 6.4$ & 6.8 & $11,6 \mathrm{a}$ \\
\hline Austrália & $82,86,94$ & & & 14.0 & 13.1 & & $17.1 \mathrm{a}$ \\
\hline Austria & 87 & & & & & 4.8 & \\
\hline Bélgica & $85,88,92$ & & & & 3.4 & 3.1 & 3.8 \\
\hline Canadá & $\begin{array}{c}71,75,81,87 \\
94\end{array}$ & 15.2 & 14.6 & 13.9 & & 13.6 & $16.0 \mathrm{a}$ \\
\hline Dinamarca & 87,92 & & & & & 5.3 & 3.3 \\
\hline EUA & $\begin{array}{c}\text { 69,74,79,86, } \\
94\end{array}$ & 13.1 & 17.3 & 18.5 & & 22.9 & $26.3 a$ \\
\hline Espanha & 91 & & & & & & $13,1 \mathrm{a}$ \\
\hline Finlândia & 87,91 & & & & & 2.9 & 2.5 \\
\hline França & $79,84,89$ & & & 6.3 & 6.5 & $9,8 \mathrm{a}$ & \\
\hline Holanda & $83,87,91$ & & & & 2.5 & 3.6 & 6.2 \\
\hline Inglaterra & $\begin{array}{c}69,74,79,86 \\
95\end{array}$ & 5.3 & 7.0 & 8,5 & & 9.9 & $21,3 \mathrm{a}$ \\
\hline Irlanda & 87 & & & & & 12.0 & \\
\hline Israel & $79,86,92$ & & & 8.2 & & 11.1 & $14,7 \mathrm{a}$ \\
\hline Itália & 86,95 & & & & & 10.8 & $21,2 \mathrm{a}$ \\
\hline Luxe $\mathrm{mb}$. & 85,94 & & & & 4.1 & & $6,3 a$ \\
\hline Noruega & $79,86,95$ & & & 3.8 & & 3.8 & $4.5 \mathrm{a}$ \\
\hline Suécia & $79,86,92$ & 3.5 & 1.9 & 3.9 & & 3.0 & $3.7 \mathrm{a}$ \\
\hline Suíça & 82 & & & & 3.3 & & \\
\hline
\end{tabular}

Fontes: Rainwater \& Smeeding (1995) e Bradbury \& Jantti (1999). Assinalado com a os indicadores extraídos de Bradbury \& Jantti (1999). O índice de pobreza é calculado como menos de $50 \%$ do rendimento médio per capita.

Ora, tem-se vindo a verificar que, ao longo destas últimas décadas, para um considerável número de países, essas percentagens, em vez de 
diminuírem, têm vindo a aumentar, de tal modo que se pode afirmar que o aumento nas desigualdades da distribuição do rendimento afectam, sobretudo, os sectores populacionais menos protegidos pelas políticas sociais, e entre estes, especialmente, as famílias mais pobres, as famílias mais jovens e as crianças. O Quadro 2, relativo às franja etário dos 0-18 anos, é ilustrativo do aumento da pobreza infanto/juvenil, na maior parte dos países ocidentais.

Uma explicação para a importância das variáveis geracionais nos indicadores de pobreza prende-se com a estrutura familiar, questão a que mais adiante nos referiremos.

Relativamente ao trabalho infantil, assinalaremos aqui apenas que as condições da modernidade tardia e da globalização, ao contrário de trazerem consigo a erradicação da exploração do trabalho de menores, criaram as condições da sua generalização, quer nos países periféricos, quer nos países semiperiféricos e centrais, nos sectores da indústria que fundam a sua competitividade nos baixos-custos da mão-de-obra assalariada. Além disso, actividades como o lazer, os espectáculos, a publicidade etc. têm vindo a inscrever de modo cada vez mais reforçado o trabalho no quotidiano das crianças.

Relativamente aos efeitos do desemprego nas gerações mais jovens, importa sublinhar a natureza estrutural das mudanças que ocorrem.

O trabalho deixou de ser a condição de ingresso no contrato social da modernidade e passou a ser, por efeito da crise do emprego, um bem escasso. O maior impacto do fenómeno do desemprego incide nos jovens, projectando-os para uma situação de "pré-contratualismo" (Santos, 1998). Com efeito, o desemprego está desigualmente distribuído entre as gerações, sendo maior entre os jovens. Em Portugal, aumenta 3 vezes a percentagem dos jovens que não têm ou nunca tiveram trabalho, relativamente à percentagem total da população activa desempregada. Por outro lado, o ingresso no mercado de trabalho faz-se, frequentemente, em condições de precariedade, abaixo do nível de qualificações e com reduzidas perspectivas de progresso, o que configura uma situação que Boaventura de Sousa Santos designou por "inclusão segundo uma lógica de exclusão” (1998, p. 29).

A ruptura entre pares de categorias que se encontraram sempre associados no período de génese e expansão da modernidade, tais como trabalho/emprego, trabalho/cidadania, emprego/vínculo profissional e qualificação/colocação profissional afectam os percursos desejáveis das crianças, reformulam as suas aspirações e condicionam as opções presentes. A crise da educação escolar radica em parte na descrença sobre a sua real 
capacidade para construir os itinerários do ingresso no mercado de trabalho. Porém, mais do que isso, promovem atitudes de competição entre as crianças e as famílias que mantêm aspirações de ingresso nas profissões mais qualificadas, com vista à obtenção de resultados escolares compatíveis com o ingresso nos cursos desejados. Todos os indicadores apontam para que essa competição se esteja a verificar de modo cada vez mais precoce e para que a ela se associe uma intensa restrição dos tempos livres das crianças, pela sua subordinação a aulas suplementares e a "explicações" que intensificam profundamente a sua jornada de trabalho. Porém, o mais perverso dos efeitos consiste na desigualdade que é gerada entre os mais novos, e os efeitos que daí decorrem nas estratégias de sobrevivência num presente que muitas crianças não vêem conduzir a qualquer futuro.

Finalmente, a criação do mercado de produtos para a infância (jogos, roupas, ténis e sapatos, vídeos, produtos informáticos, livros, serviços dos mais diversos, parques temáticos, rotas de turismo infanto-juvenil, guloseimas etc.) para além dos efeitos que produz na uniformização de gostos e estilos de comportamento e de vida, gera, pelos custos que a obtenção desses produtos implica nas famílias e pela apetência gerada pelo marketing e publicidade, novas estratificações, sendo as crianças pobres remetidas para a condição de exclusão perante os seus pares, por menor acesso ao consumo. As desigualdades tendem, deste modo, a ser constituídas nas relações de pares, pela perversidade do fetichismo da mercadoria e pela inculcação dos valores do mercado nas gerações mais jovens.

Podemos conferir os dados sobre a situação das crianças face à produção e ao consumo com a análise das mudanças que ocorrem no

\section{espaço doméstico.}

Os últimos trinta anos têm vindo a acentuar uma profunda ruptura da instituição familiar nas suas facetas formal e familialista, tendo todos os indicadores revelado a quebra das taxas de nupcialidade, o aumento do número de divórcios, o aumento do nascimento dos filhos fora do casamento, o incremento dos grupos domésticos de pessoas sós ou de famílias recompostas.

Importa também referir que se verifica um aumento da pobreza infantil sempre que se passa de uma estrutura de família nuclear para uma situação de família monoparental ou de família desestruturada. Isso mesmo é evidenciado no Quadro 3.

Não se pode, no entanto, presumir que exista uma relação linear e determinística entre ruptura na estrutura familiar tradicional e aumento da pobreza infantil. Esta decorre de outros factores, já assinalados atrás. 
O que se evidencia é, antes, uma reestruturação da família tradicional que deixa de ser, pelo menos nos mesmos termos em que o foi no passado recente, a instância de inserção e protecção económica dos mais novos. Por outro lado, o crescimento da percentagem de tipologias diferenciadas de famílias arrasta consigo necessidades específicas de proteç̧ão às famílias não nucleares, o que, não tendo sido até agora adequadamente considerado, permite que o anátema social que incide por exemplo sobre mães solteiras ou sobre outros tipos menos tradicionais de vivência da maternidade ou da conjugalidade - ainda que esse anátema ocorra diferenciadamente de acordo com o contexto social - acresça às condições específicas de exclusão e de pobreza. Importa também assinalar que alguns indicadores mostram uma correlação estatística entre as baixas condições económicas e o número elevado de filhos (Almeida et al., 1998).

As mudanças estruturais e culturais na instituição familiar mostram, por outro lado, que a família tem vindo a perder de modo progressivo e significativo o estatuto de instância primeira de socialização, por efeito das sucessivas recomposições e reestruturações que tem sofrido. Esse estatuto tende a deslocar-se para o espaço público, seja ele o das instituições estatais, seja o da rua ou o do bairro, espaços estes geradores de novos processos de referência e de sociabilidades nas novas gerações.

\section{Quadro3}

Taxa de pobreza infantil por tipo de família

\begin{tabular}{|c|c|c|c|c|}
\hline País & Ano & Mãe sozinha & Dois pais & $\begin{array}{c}\text { Outro tipo } \\
\text { de família }\end{array}$ \\
\hline Ale m anha & 1994 & 43,3 & 8,5 & 7,3 \\
\hline Austrália & 1994 & 38,3 & 14,7 & 16,6 \\
\hline Austria & 1987 & 33,2 & 2,9 & 2,0 \\
\hline Bélgica & 1992 & 11,8 & 6,1 & 3,0 \\
\hline Canadá & 1994 & 45,3 & 12,3 & 13,4 \\
\hline Dinam arca & 1992 & 10,5 & 5,5 & 2,8 \\
\hline EUA & 1994 & 59,6 & 16,7 & 29,1 \\
\hline Eslo váquia & 1992 & 7,6 & 2,1 & 1,4 \\
\hline Espanha & 1990 & 25,2 & 12,4 & 13,5 \\
\hline Finlândia & 1991 & 6,2 & 3,0 & 4,1 \\
\hline França & 1989 & 25,4 & 7,7 & 12,6 \\
\hline Ho landa & 1991 & 29,6 & 6,8 & 4,2 \\
\hline Hungria & 1994 & 12,0 & 10,9 & 12,9 \\
\hline Inglaterra & 1995 & 40,3 & 17,5 & 13,9 \\
\hline
\end{tabular}




\begin{tabular}{|c|c|c|c|c|}
\hline Hungria & 1994 & 12,0 & 10,9 & 12,9 \\
\hline Inglaterra & 1995 & 40,3 & 17,5 & 13,9 \\
\hline Irlanda & 1987 & 29,8 & 16,7 & 7,1 \\
\hline Israel & 1992 & 26,6 & 14,0 & 14,8 \\
\hline Itália & 1995 & 20,2 & 20,9 & 22,3 \\
\hline Luxemburgo & 1994 & 30,1 & 4,4 & 6,8 \\
\hline No ruega & 1995 & 10,4 & 3,4 & 4,4 \\
\hline Po lónia & 1992 & 4,9 & 13,7 & 17,5 \\
\hline Rep. Checa & 1992 & 8,9 & 1,3 & 1,4 \\
\hline Rússia & 1995 & 31,0 & 26,0 & 26,5 \\
\hline Suécia & 1992 & 4,5 & 3,6 & 2,6 \\
\hline Suíça & 1982 & 21,2 & 4,8 & 12,5 \\
\hline Taiw an & 1995 & 15,2 & 5,1 & 7,5 \\
\hline
\end{tabular}

Fonte: Bradbury \& Jantti (1999).

O espaço da cidadania que, desde o início da modernidade, com a criação da escola pública, disputou às famílias a socialização dos mais novos, vê-se hoje confrontado com novas instâncias socializadoras. Importa, pois, fazer um balanço.

À escola pública se deve, em boa parte, o sucesso de alguns dos principais "mitos legitimadores" (Ramirez \& Boli, 1987) em que assentou a modernidade: o mito do individualismo, o mito da nação como agregado de indivíduos, o mito do progresso nacional e individual, o mito da socialização e continuidade do ciclo de vida e o mito do Estado como guardião da Nação. O fenómeno de descontextualização e globalização das sociedades, numa fase de modernidade avançada, a par da transformação e disseminação dos meios de produção e difusão de saberes, bem como da afirmação no plano social de culturas alternativas à cultura padrão (e, entre elas, as culturas infantis e juvenis), explica a instalação da crise das escolas a nível mundial. Esta é uma crise institucional da escola de massas. Ora, a crise dos mitos legitimadores permite dar visibilidade à lógica social da educação, pondo em causa a própria escola.

É uma situação dessas, aquela que precisamente parece estar a ocorrer. É hoje corrente a constatação de que "a instituição escolar tende a aparecer cada vez mais, tanto às famílias como aos próprios alunos, como um logro, fonte de uma imensa decepção colectiva” (Bourdieu \& Champagne, 1993, p. 600). Numa situação de crise generalizada do emprego, a escola torna-se, simultaneamente, o espaço próprio da acomodação das fileiras de crianças e de jovens, que de outro modo estariam em situação de absoluta desocupação, e, para a maioria da 
população que não consegue à partida garantir uma actividade social remunerada para o futuro dos seus filhos, o espaço mirífico da aquisição da certificação que, como que magicamente, se destina a transpor as (de outro modo insuperáveis) barreiras colocadas no acesso a uma profissão prestigiada. Porém, não apenas essa certificação tende a ser progressivamente diferida, por efeito da inflação das credenciais e pelo alargamento contínuo dos níveis de escolaridade obrigatória e das taxas de frequência, como, mesmo quando obtida, não tem já o valor social que lhe era imaginariamente atribuído, pelo estabelecimento de mecanismos não escolares de cooptação de quadros e de alocação de recursos.

Estabelece-se, deste modo, uma crise que abala já não apenas os processos de acção educativa e os modelos pedagógicos, mas se dirige ao coração mesmo da dimensão institucional da escola. Esta crise associa-se ao crescimento dos movimentos juvenis e à génese de uma cultura contra a escola (e.g. Willis, 1991; Giroux, 1994), que se exprime de variadas formas, sendo apenas uma delas a disrupção escolar e a assunção de comportamentos desviantes ou anómicos.

A crise da instituição escolar, sendo estrutural, não pode ter uma resposta exclusivamente pedagógica. Há dimensões políticas que se relacionam com dois domínios centrais. A reabilitação da escola pública enquanto espaço cívico de formação - incluindo de formação para o trabalho, no sentido da "redescoberta democrática do trabalho" (Santos, 1998) - e a mobilização da participação das crianças e dos jovens na refundação dos sentidos para uma instituição que os ocupa cada vez mais, no sentido da promoção de "lógicas da acção" (Sarmento, 2000) que habilitem a escola como instância promotora da cidadania.

Esta questão prende-se directamente com a participação política das gerações mais jovens. Concebida frequentemente como modo de cooptação pelos partidos "adultos”, através das "juventudes partidárias" (que reúnem os respectivos militantes até aos 30 anos...), a participação política das crianças (sobretudo das crianças que frequentam os níveis terminais da escola básica e no ensino secundário) exprime-se mais frequentemente noutros espaços menos institucionalizados e convocam para a agenda política temas e questões que acabam por ganhar uma insuspeitável importância (como tem sido claramente o caso, nas últimas décadas, de questões como a da escola, a da segurança urbana, a do ambiente, a do reconhecimento de direitos a formas alternativas de vida etc.). Mobilizar essa participação para o espaço público, sem que por esse efeito se gere a colonização dos mundos de vida infanto-juvenis, é 
hoje uma dimensão importante na inserção de jovens e um ponto central da renovação democrática. Esta questão passa pelo reconhecimento dos direitos de participação das crianças na constituição do espaço público e pela mobilização expressiva da sua opinião, segundo modalidades e fórmulas imaginativas e diversificadas.

Este ponto é decisivo, quer numa efectiva expressão dos direitos das crianças, quer no confronto com um dos mais assinaláveis indicadores de exclusão: o da participação política e da vida democrática, pela não detenção do direito de voto.

Este último ponto articula-se directamente com o último espaço estrutural que define a condição da infância na modernidade tardia: o

\section{espaço comunitário.}

A interaç̧ão entre as crianças é, para além de uma condição fundamental do desenvolvimento de relações e de laços de sociabilidade - e, por isso, um dos mais importantes factores da "educação oculta" das crianças - o espaço onde se estabelecem os valores e os sistemas simbólicos que configuram as culturas infantis (Corsaro, 1997). A afirmação, frequentemente colhida nos inquéritos às crianças em idade escolar, de que elas gostam de "ir à escola", mesmo quando não gostam de "ir às aulas", testemunha o sentimento de pertença a um grupo de pares, e a uma cultura geracional.

De certo modo, pode afirmar-se que as gerações jovens transferem para o espaço das solidariedades grupais no espaço comunitário as vinculações que na fase inicial da modernidade se estabeleciam no interior do círculo doméstico ou da escola.

A característica essencial da relação comunitária é a construção colectiva dos horizontes de referência, dos valores e das pautas de conduta. De algum modo, a reciprocidade de relações e a horizontalidade na distribuição de poderes são inerentes à pertença comunitária. No entanto, importa distinguir entre laços comunitários que se estabelecem pela formação de fronteiras (mesmo quando aceitam a reciprocidade interna, eles são profundamente exclusionistas para o seu exterior) e laços comunitários abertos e integrativos. ${ }^{2}$

As culturas infantis participam e constróem(-se) (n)os dois tipos de comunidades. Como exemplo das primeiras, os bandos de bairro, frequentemente (mas nem sempre) associados a pertenças étnicas exclusivas, correspondem a formas de construção exclusionista de solidariedades, por parte de quem já experimentou a exclusão da sociedade. Aliás, a formação de uma cultura grupal ocorre normalmente 
nas “crianças de rua” (Sebastião, 1997). A patologização destes bandos - e a sua imediata conotação com práticas desviantes e/ou delinquentes - constitui um importante factor de incompreensão das formas grupais de constituição das culturas infanto-juvenis e é um elemento adicional de exclusão social de crianças que, normalmente, vivem já em contextos caracterizados por outros indicadores de exclusão (pobreza, degradação urbana etc.). Além do mais, essa patologização decorre do facto desses bandos infanto-juvenis de bairro constituírem formas de resistência às práticas paternalistas (Scraton, 1997) e de, frequentemente, serem espaços de solidariedade hostil às ameaças do mundo autoritário dos adultos. Esses bandos, porém, comportam geralmente formas muito criativas de expressão das culturas de crianças e jovens (as músicas Rap, associadas a grupos infanto-juvenis euro-africanos ou afro-americanos são um exemplo disso). A sua configuração como espaços de sociabilidade e de cultura apresenta-se, portanto, como essencial na compreensão da sua natureza.

Normalmente menos estruturadas, as formas comunitárias integrativas de pertença infantil encontram-se, por exemplo, nos festivais, nas festas (por exemplo, nas festas de aniversário, cf. Sirota, 1999) ou nos grupos informais com que se constrói a sociabilidade multicultural e cosmopolita da infância contemporânea. Neste caso, porém, é menos provável encontrarmo-nos perante exclusão social.

As dimensões estruturais que acabámos de referir não nos devem fazer esquecer que as crianças participam de modo diferenciado na vida em sociedade. Essa diferenciação não é exclusivamente individual. Há outras dimensões estruturais que se cruzam com as categoria social da infância e que colocam cada ser social numa topografia complexa de relações. Apesar da crescente uniformização de estilos de vida, não é indiferente ser-se rapaz ou rapariga. As relações de género atravessam não apenas as identidades pessoais como impõem constrangimentos sociais próprios. Não se fala de "gravidez juvenil”, por exemplo, mas de "gravidez das adolescentes”. Do mesmo modo, a posição social das crianças, ou a sua pertença étnica ou ainda a sua inserção geográfica (central ou periférica, urbana ou rural, no bairro urbano de classe média ou nos subúrbios etc.) são categorias fundamentais na respectiva identidade. A heterogeneidade que aqui se desenha implica que se problematize a complexidade destas pertenças estruturais e que se pense nos processos de exclusão social - e, alternativamente, nas políticas de inclusão - a partir, simultaneamente, dos factores de homogeneidade e dos factores de heterogeneidade se conjugam na situação social das criança. 
Que pode a escola contra a exclusão social? Sendo um fenómeno estrutural, a escola pode pouco. Mas é esse pouco que pode ser incomensurável se o projecto educacional fôr uma forma de garantir um processo político-pedagógico de transformação social e institucional. Por outras palavras, se se assumir a educação como "política da vida" (Giddens, 1994), ou seja, algo que existe para ser transformado e que, no seu presente, é percepcionado como um projecto pessoal e social, mobilizador da capacidade de transformação e de mudança que os actores educativos possuem.

É no quadro da Escola como política da vida - da Escola como utopia realizável - que julgo ser sustentável uma lógica alternativa para a educação escolar, contra a exclusão e pela afirmação dos direitos sociais.

Em primeiro lugar, é indispensável quebrar com tudo aquilo que são os elementos simbólicos que constituem o senso comum da acção educativa, por parte dos professores e dos restantes elementos da comunidade educativa e que conduzem à exclusão dos saberes das crianças dos grupos sociais das classes populares e das minorias étnicas e culturais. Este quebrar do senso comum - isto é, dos elementos simbólicos fundadores institucionalizados da escola - é, sobretudo, um trabalho de aprendizagem. A aprendizagem organizacional da escola e a capacidade de tornar a escola uma organização aprendente é o primeiro e decisivo elemento na transformação da escola no sentido dessa utopia realizável.

Isto significa aprender tudo de novo, fundamentar tudo de novo, obrigar a repensar os adquiridos, combater através de um esforço de reflexividade, os efeitos de institucionalização da escola. Estes são efeitos seculares, ou seja, a escola hoje tem de procurar encontrar o seu caminho e este trabalho de aprendizagem coloca claramente nas mãos das comunidades educativas, e muito em particular nos professores, o esforço de pensar a sua acção. É hoje indispensável repensar a escola para além das normas, repensar os seus fundamentos, repensar os seus projectos e este é um trabalho que mais ninguém poderá fazer.

Em segundo lugar, a escola poderá reconstituir-se e refundar-se civicamente se for capaz de fazer o cruzamento com uma lógica emergente, que é a lógica dos direitos da criança.

Quando, anos atrás, ocorreu a comemoração dos 50 anos dos Direitos do Homem, participei numa acção numa escola onde um velho professor meu disse uma coisa que acho muito impressiva e que é necessário 
repetir: "uma escola que nos 50 anos da proclamação da declaração dos Direitos do Homem não festejou essa data, não merece abrir as suas portas”. É verdade, também, que uma escola que não se articula com os direitos da criança não merece abrir as suas portas. Esta articulação entre a lógica educativa e os direitos da criança, em todas as suas dimensões, é um esforço absolutamente essencial. Porém, não se deram ainda muitos passos, nem muito menos passos seguros, nesse sentido.

Em terceiro lugar, o regresso da pedagogia, o regresso à questão dos saberes e da forma como esses saberes são aprendidos, é uma questão central em todas as políticas educativas não excludentes. Paradoxalmente, esta é uma questão sobre a qual se sabe muito pouco - designadamente as Ciências da Educação sabem muito pouco acerca do modo como se aprende -, sobretudo em contextos multiculturais. Bernard Charlot, que é um dos investigadores que mais tem estudado este tema, publicou recentemente um livro cuja conclusão fundamental é exactamente essa: há uma manifesta insuficiência do conhecimento adquirido acerca do modo como os meninos ou como as meninas das classes populares se articulam com os saberes escolares, os incorporam, os investem no seu discurso, e realizam todo o processo de codificação do conhecimento (Charlot et al., 1999). Isto significa uma enorme exigência no âmbito da aprendizagem organizacional e da construção da escola como organização aprendente. O que está em causa é perceber como os saberes se tornam mais significativos, mais desejados e mais susceptíveis de provocar a felicidade nos alunos e promover a sua cidadania activa.

Finalmente, conceber a educação como política da vida consiste em imprimir uma dinâmica organizacional que pode ser sumariada em quatro pontos:

Primeiro, pensar o trabalho docente como um trabalho de grupo, colaborativo e participativo. O trabalho docente não é um trabalho solitário do professor na sala de aula, mas é o trabalho de uma equipa, e só é susceptível de ser realizado enquanto fôr o trabalho de uma equipa que se coordena, que se articula, que se combina e que actua em conjunto.

Em segundo lugar, no âmbito dessa dinâmica organizacional, pensar a escola como um elo de uma política social. Construir a educação como política social significa duas coisas: primeira, que a educação é uma componente que só faz sentido quando associada às outras comoponentes das políticas sociais que podem realizar a inclusão social: políticas de saúde, de habitação, de solidariedade e protecção social etc. Esta é uma questão, sobretudo, de projecto político enfatizador da dimensão da 
inserção e participação social. Segunda, que as práticas educativas devem considerar a dimensão holística da pessoa dos educandos e, por isso mesmo, elas devem também conter essas mesmas dimensões de promoção da saúde e do bem-estar das crianças em todas as suas dimensões. Esta é uma questão de projecto político-pedagógico.

Em terceiro lugar, pensar a escola como um projecto da renovação da tradição. A ideia da inovação como renovação da tradição é um elemento central na construção de uma escola para a inclusão social. A escola, hoje, não pode fazer muito mais coisas do que aquilo que fez no passado nomeadamente quando, na primeira modernidade, se erigiu como um baluarte da afirmação dos direitos de cidadania e da promoção da liberdade, igualdade e fraternidade. Simplesmente tem de fazer o que sempre fez de modo radicalmente diferente. É no sentido de que faz de modo diferente aquilo que fez no passado que garante a renovação do projecto moderno e, portanto, que permite a reinvenção cívica da Escola pública.

E, finalmente, é preciso não esquecer o papel do Estado na Educação. Não apenas se encontra em causa a defesa de um investimento público mais intenso, ao arrepio das orientações neo-liberais dominantes, como se torna indispensável uma renovação da própria forma de regulação e administração da educação e das escolas. Trata-se de facto de um outro tipo de aparelho de Estado e de prática da administração: uma administração clínica, não o controlo burocrático; uma administração que não se esgote na regulação normativa, mas que se revele como a supervisão capaz de providenciar apoio, ajuda, colaboração e a intervenção reguladora contra as desigualdades e pela equidade.

\section{Conclusão}

De "utopia realizável" falei um pouco mais acima, na defesa da mudança educacional, para uma escola da inclusão e dos direitos. Haverá ainda direito à utopia (parafraseando Adorno) depois de Auchwitz, da globalização capitalista hegemónica, do belicismo galopante, do incremento exponencial das desigualdades, da violação contínua dos direitos das crianças e do homem? A resposta só pode ser: mais do que nunca há agora não apenas o direito, mas o dever de construir e realizar a utopia, mesmo que isso seja a única coisa que nos resta fazer.

São os momentos crepusculares - como o que vivemos - aqueles que também permitem antecipar a visão dos dias e dos factos da vida. Estes são também momentos em que as crianças aparecem como o presente de um futuro renovado. 
Comecei com uma imagem visual: a das cruzadas das crianças. Gostaria de terminar também com uma imagem, esta agora musical: em 1931, nas vésperas da ascensão de Hitler ao poder na Alemanha, cantavase nos cabarets de Berlim uma canção que apelava, no desespero premonitório da barbárie nazi, à utopia de uma paz perene construída pelas crianças. São os versos dessa canção de cabaret (cantada por Ute Lemper), que vos deixo, sem premonições, mas com a reafirmação atenta de um projecto de uma vida vivível e fraterna, como música de fundo:

Eu vejo uma terra que baniu a guerra

E fundiu todos os canhões

Para construir um barco de amor para as crianças

Que pretendam viajar de cidade em cidade

Declarando a paz por todo o mundo.

Deixem de assassinar já

(...).

Todos os conflitos cessarão agora

E cada um de nós viverá em paz...

Recebido em novembro de 2001.

Aprovado em fevereiro de 2002.

\section{Notas}

1. Sousa Santos refere seis espaços estruturais: doméstico, da produção, do mercado, da comunidade, da cidadania e, por último, o espaço mundial.

2. Sousa Santos (1994) distingue entre "comunidades-fortaleza" e "comunidades-fronteira", para assinalar comunidades fechadas ou abertas, respectivamente.

Referências bibliográficas

ALMEIDA, Ana Nunes de et al. "Relações familiares: Mudança e diversidade”. In: Viegas, J.M.L.; Costa, A.F. (Orgs.), Portugal, que Modernidade? Oeiras: Celta Editora, 1998.

ARIÉS, Philip. L'enfant et la vie familiale sous l'Ancien Régime. Paris: Seuil, 1973.

BOURDIEU, Pierre; CHAMPAGNE, Patrick. "Les exclus de l'interieur". In: Bourdieu, P. (Dir.), La misére du monde, Paris: Seuil, 1993. 
BRADBURY, Bruce ;JANTTI, Markus. Child poverty across industrialized nations. Innocenti Ocacasional Papers, 71. Florence: UnICEF, 1999.

CASTELLS, Manuel. "Fujos, redes e identidades: Una teoria crítica de la sociedad informacional". In: CASTELLS, M. et al., Nuevas perspectivas críticas en Educación, Barcelona: Paidós, 1994.

CHARLOT, Bernard; BAUTIER, Elisabeth; ROCHEX, Jean-Yves. Ecole et savoir dans les Banlieux et Ailleurs. Paris: Armand Collin, 1999.

CORSARO, William A. The sociology of childhood. Thousand Oaks: Pine Forge Press, 1997.

GIDDENS, Anthony. The constitution of society. Outline of the Theory of Structuration. Cambridge: Polity Press, 1984.

- Modernidade e identidade pessoal. Oeiras: Celta Editora, 1994.

GIROUX, Henry A. "Jovenes, diferencia y educación postmoderna”. In: CASTells, M. et al., Nuevas perspectivas críticas en Educación, Barcelona: Paidós, 1994.

RAINWATER, L; SMEEDING, T.M. Doing poorly: The real income of American children in a comparative perspective. Syracuse: Syracuse University-Working Paper n⿳⺈⿴囗十⿺辶万 1995.

RAMIREZ, Francisco O.; BOLI, John. The political construction of mass schooling: European origins and worldwide institutionalization. Sociology of Education, $\mathrm{n}^{\mathrm{a}}$ 60, 1987, p. 2-17.

SANTOS, Boaventura de Sousa. Pela mão de Alice: O social e o político na Pós-Modernidade. Porto: Afrontamento, 1994.

. Reinventar a democracia. Lisboa: Fundação Mário Soares/ Gradiva, 1998.

- A crítica da razão indolente. Contra o desperdício da experiência. Porto: Afrontamento, 2000.

SARMENTO, Manuel Jacinto. Lógicas da acção nas escolas. Lisboa: Instituto de Inovação Educacional, 2000.

.; PINTO, Manuel. "As crianças e a infância: Definindo conceitos, delimitando o campo". In: Pinto, M.; SARMENTo, M.J. (Coords.), As crianças: Contextos e identidades. Braga: Instituto de Estudos da Criança da Universidade do Minho, 1997. 
SARMENTO, Manuel Jacinto et al. "A escola e o trabalho em tempos cruzados.” In: Pinto, M.; Sarmento, M.J. (Coords.), As crianças: Contextos e identidades, Braga: Instituto de Estudos da Criança da Universidade do Minho, 1997.

SCRATON, Phil. "Whose 'childhood' what 'crisis'?" In: SCRATON, P. (Ed.). Childhood in 'crisis'?, London: UCL Press, 1997, p. 163186.

SEBASTIÃO, João. As crianças de rua. Oeiras: Celta Editora, 1995.

SGRITTA, Giovanni B. Inconsistencies: Childhood on economic and political agenda. Comunicação à Conferência "Childhood and Children's Culture", Esbjerg, Dinamarca, 30 de maio a 2 de Junho (polic.), 1997.

SIROTA, Regine. Les civilités de l'enfance contemporaine. L'anniversaire ou le déchiffrage d'une configuration. Éducation et Sociétés, 1999, $\mathrm{n}^{\mathrm{a}}$ 3, p. 31-54.

UNICEF. Situação Mundial da Infância 2000. Brasília: UnICEF, 2000.

WILLIS, Paul. Aprendendo a ser trabalhador. Escola, resistência e reprodução social. Porto Alegre, 1991. 